\title{
The Risk of Non-Traumatic Myelopathy in Time Trial (TT) or Downhill (DH) Bike Position
}

Keiji Sugiura* and Mariko Sugiura

Department of Environmental Dermatology and Allergology, Daiichi Clinic, Nagoya, Japan

"Corresponding author: Keiji Sugiura, Department of Environmental Dermatology and Allergology, Daiichi Clinic, Nagoya, Japan, Tel: +81-52-204-0834; E-mail: ksugiura@daiichiclinic.jp

Received date: December 16, 2016; Accepted date: December 21, 2016; Published date: December 28, 2016

Copyright: ( 2016 Sugiura K, et al. This is an open-access article distributed under the terms of the Creative Commons Attribution License, which permits unrestricted use, distribution and reproduction in any medium, provided the original author and source are credited.

Keywords: Myelopathy; Triathlon; Surfer; Athlete; Cycling

\section{Introduction}

\section{The form in cycling}

The time trial (TT) or downhill (DH) position (Figure 1) in cycling, which is different from general riding form, is used in time trial road races or triathlons to decrease air resistance and achieve faster speeds. In the TT or DH position, the rider's neck is extended and his or her body is strained while racing, and some athletes develop neck pain or headache. Most cases of neck pain may be caused by fatigue due to sustained muscular stress, but there may be some risk of myelopathy in some cases.

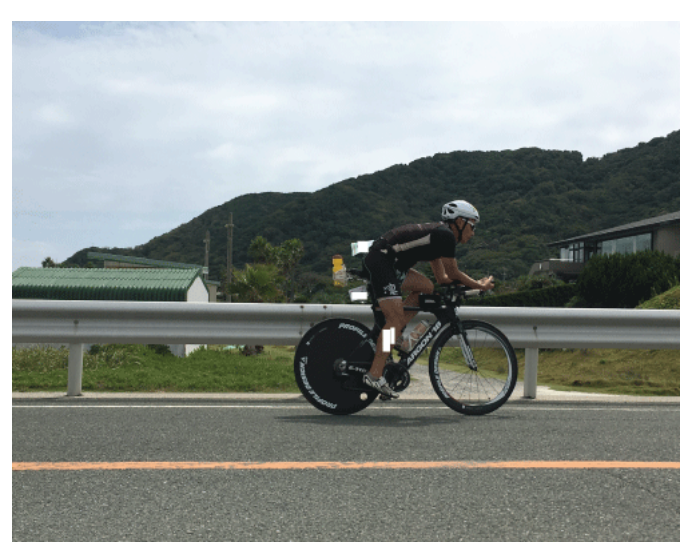

Figure 1: Time trial (TT) or downhill (DH) position.

Triathlons involve different distances, and there are also many different styles of bicycle; likewise, different athletes have different racing experiences and different body conditions. However, the TT position or $\mathrm{DH}$ position is common and many cyclists can use $\mathrm{DH}$ bars for faster speed.

\section{Myelopathy}

Ischemia of the spinal cord accounts for approximately $6 \%$ of all acute myelopathies and 1-2\% of all vascular neurologic pathologies [1]. Surfer's myelopathy is rare and not well-known, but this myelopathy is an emergent neurological condition. Thompson [2] reports that risk factors for surfer's myelopathy include body habitus (underdeveloped musculature), dehydration, and long-distance travel (hypercoagulable state and deep venous thrombosis). Most triathletes experience these same risk factors, which may then come into play, especially in long distance races using the TT or DH position.

Generally, cyclists essentially prop themselves up by gripping their handles. Up to $60 \%$ of cyclists develop neck and back pain [3]. Most of these are not myelopathy, the cervical muscles have not adapted by increasing maximal isometric strength, and the neck pain may simply be caused by fatigue from the sustained muscular contraction required by cycling [4]. Ulnar neuropathy (tingling, numbness, and weakness in the hands) is common in serious cyclists after several days of riding [3]. These symptoms are different from those seen in surfer's myelopathy and suspected in myelopathy due to the TT position or DH bike position. Surfer's myelopathy is the result of an ischemic event because vessels (vein and artery systems) in the spinal cord are thin and chartered by anatomic systems [5-8]. There have been various reports on the mechanisms of surfer's myelopathy, such as increased tension on both the spinal cord and surrounding vascular structure [9], causing possible avulsion or perforating of vessels and secondary vasospasm leading to transient ischemia [9], vasospasm of the artery of Adamkewicz, transient ischemia in areas of borderline perfusion, inferior vena cava obstruction $[2,10]$, fibrocartilaginous embolism, and paddling (compression by the liver and Valsalva maneuver) cause increasing retrograde venous pressure in the epidural venous plexuses and possibly ultimately leading to infarction [10].

\section{The risk of myelopathy in cycling}

Our speculation regarding TT or DH position myelopathy is as follows. This myelopathy may be seen in novices with undeveloped or underdeveloped musculature, or may be associated with an improperly adjusted bike, soma type, low flexibility of the spine, and/or vascular abnormalities. Ischemic myelopathy may be triggered by prolonged TT or DH position with neck hyperextension while using DH bars. The extended position of the neck, which may increase intra-spinal pressure, can cause increased pressure during the Valsalva maneuver and, together with dehydration and/or some obstruction in arterial blood circulation or backflow of venous blood, might lead to the development of an ischemic condition of the spinal cord. Most athletes work hard with tense during cycling in the TT or DH position, and an increased cardiac rate and output may promote ischemia of the spinal cord. Additionally, many athletes travel for long periods of time, which may cause hypercoagulable state or deep venous thrombosis [2].

\section{Conclusion}

Non-traumatic and ischemic myelopathy, which may develop in cyclists using the TT or DH position, is a minor syndrome and a new concept of myelopathy in triathletes that physicians may encounter in cyclists who race. Some athletes develop neck pain, headache, and 
numbness of arms (hands) or legs when using the TT or DH position with neck extension and strained body. Not all instances of these symptoms are myelopathy, but a few cases may involve mild myelopathy. Because many athletes change riding position in cycling there may be very few cases of complete myelopathy.

To date, we have experienced no patients with this myelopathy, and this report is intended solely to raise awareness of the possibility of this myelopathy among athletes and physicians. For athletes, we recommend education and awareness to prevent $\mathrm{TT}$ or $\mathrm{DH}$ position myelopathy and to avoid progressive deterioration of neurologic function. It is essential to adjust one's bicycle to obtain an appropriate riding position and to rehydrate appropriately.

\section{To Athletes}

Calling for help and retiring in competition are important for preventing serious condition and are not shaming.

\section{References}

1. Sandson TA, Friedman JH (1989) Spinal cord infarction: report of 8 cases and review of the literature. Medicine 68: 282-292.

2. Thompson TP, Pearce J, Chang G, Madamba J (2004) Surfer's myelopathy. Spine (Phila Pa 1976) 29: E353-356.
3. Mellion MB (1991) Common cycling injuries. Management and prevention. Sports Med Jan 11: 52-70.

4. Jacobs K, Nichols J, Holmes B, Buono M (1995) Isometric cervical extension strength of recreational and experienced cyclists. Can J Appl Physiol 20: 230-239.

5. Vargas MI, Gariani J, Sztajzel R, Barnaure-Nachbar I, Delattre BM, et al. (2015) Spinal cord ischemia: Practical imaging tips, pearls, and pitfalls. AJNR Am J Neuroradiol 36: 825-830.

6. Bowen BC, DePrima S, Pattany PM, Marcillo A, Madsen P, et al. (1996) MR angiography of normal intradural vessels of the thoracolumbar spine. AJNR Am J Neuroradiol 17: 483-494.

7. Thron AK (2008) Vascular anatomy of the spine and spinal cord. In: Hurst RW, Rosenwasser RH (eds.) Interventional Neuroradiology. Informa Healthcare, New York. pp: 39- 55.

8. Moes P, Maillot C (1981) Superficial veins of the human spinal cord: an attempt at classification [in French]. Arch Anat Histol Embryol 64: 5-110.

9. Maharaj MM, Phan K, Hariswamy S, Rao PJ (2016) Surfer's myelopathy: A rare presentation in a non-surfing setting and review of the literature. J Spine Surg 2: 222-226.

10. Israel Aviles-Hernandez, Inigo Garcia-Zozaya, DeVillasante JM (2007) Nontraumatic myelopathy associated with surfing. J Spinal Cord Med 30: 288-293. 